Check for updates

Cite this: RSC Adv., 2018, 8, 36441

Received 20th September 2018 Accepted 22nd October 2018

DOI: $10.1039 / c 8 r a 07817 c$

rsc.li/rsc-advances

\section{Reprocessable and recyclable styrene-based resins with low dielectric and good mechanical properties $\dagger$}

\author{
Yang Xiong, ${ }^{a b}$ Lili Liu, (D) ${ }^{b}$ Chengyao Hu, ${ }^{b}$ Yawen Huang, id *a Xiuli Zhaoc \\ and Junxiao Yang ${ }^{a}$
}

Current low dielectric materials can't be recycled, causing significant serious environmental pollution. In this work, to create a type of recyclable and reprocessable low dielectric materials, pyridine was incorporated into styrene-based polymers by copolymerization. Subsequently, this copolymer was cross-linked by incorporating zinc ions and forming coordination bonds. These resins exhibited low dielectric constant $(\varepsilon$ $=\sim 3$ ) and good tensile strength ( 40 MPa) and modules ( 700 MPa). Meanwhile, these resins can be decrosslinked and dissolved in tetrahydrofuran and be reprocessed at above $200{ }^{\circ} \mathrm{C}$. After 3 cycles of reprocessing, the low $\varepsilon$ and mechanical properties of the styrene resins can still be preserved, indicating a good recyclability of these new styrene-based resins.

\section{Introduction}

Low dielectric permittivity (low-k) materials have been widely used in (micro)electronic packaging and wave transmitting. ${ }^{1}$ However, most of these low dielectric materials contain static covalent cross-links that preclude the recycling of cured polymer networks. ${ }^{2}$ As a result, a large number of low dielectric materials and derived products are scrapped each year, causing serious environmental pollution and resource waste. Recently, sustainable polymers, in particular reprocessable and recyclable polymers, have aroused much attention. In reprocessable polymers, cross-linked networks are constructed based on dynamic bonds, ${ }^{3}$ typically employing reversible Diels-Alder chemistry ${ }^{4}$ or the concept of "vitrimers" proposed by Leibler et al. ${ }^{5}$ However, cross-linking networks via covalent bonds are generally difficult to relieve as harsh conditions are required. This is undesirable for the recycling of low-dielectric materials from microelectronic devices.

Apart from dynamic covalent bonds, non-covalent dynamic bonds have also been used to build reversible cross-linking network, in particular for elastomers and hydrogels. ${ }^{6}$ In contrast, thermosets with non-covalent dynamic bonds have rarely been explored because non-covalent dynamic bonds were

\footnotetext{
${ }^{a}$ State Key Laboratory of Environmental-friendly Energy Materials, Southwest University of Science and Technology, Mianyang 621010, China

${ }^{b}$ School of Material Science and Engineering, Southwest University of Science and Technology, Mianyang, Sichuan 621010, China

'Institute of Chemical Materials, China Academy of Engineering Physics, Mianyang 621900, China.E-mail: zhxl75@163.com

$\dagger$ Electronic supplementary information (ESI) available. See DOI: $10.1039 / \mathrm{c} 8 \mathrm{ra} 07817 \mathrm{c}$
}

conventionally considered as weak bonds and were unfavorable to preserve high mechanical strength. Coordination bonds are a family of typical non-covalent dynamic bonds but exhibit several unique properties. ${ }^{7}$ First, their bonding energy is generally higher than that of other non-covalent dynamic bonds. Second, thermosets cross-linked by coordination bonds are easy to relieve cross-linking owing to their feature of dynamic bonds.

Inspired by above idea, in this work, coordination bonds were introduced in styrene resins to create new recyclable and reprocessable low-dielectric materials. Styrene resins are one of industrialized polymeric materials with low-dielectric properties $(k<2.7)$ and have been widely used in low dielectric applications. To introduce coordination bonds in styrene resins, 4-vinylpyridine was copolymerized with styrene to produce styrene polymers with ligands. Such polymers were cross-linked by introducing zinc chloride and forming coordination bonds. The molding of as-resulted cross-linked styrene resins produced samples for further characterization. The styrene resins exhibited low-dielectric properties and good mechanical strength. Meanwhile, they are recyclable by dissolving in THF and reprocessable at $200^{\circ} \mathrm{C}$ under pressure. The reprocessing was demonstrated to preserve the low-k and mechanical strength.

\section{Experimental}

\section{Materials}

Vinylpyridine (VP) and divinylbenzene (DVB) were provided by Aladdin (China). Styrene, benzoylperoxide (BPO) and organic solvents were provided by Chengdu Kelong Chemical Reagent 
Co. (China) and used without further purification. Zinc chloride $\left(\mathrm{ZnCl}_{2}\right)$ was purchased from Xilong Chemical Co., Ltd (China).

\section{Preparation of styrene-4-vinylpyridine copolymer (PSVP)}

PSVP was prepared by bulk polymerization in a $50 \mathrm{ml}$ anaerobic bottle with magnetic stirring. Typical experiment was as following: styrene $(8.0 \mathrm{~g}, 0.076 \mathrm{~mol})$, vinylpyridine $(0.89 \mathrm{~g}$, $0.0085 \mathrm{~mol}$ ) and benzoylperoxide (BPO, $0.06 \mathrm{~g}, 5 \mathrm{wt} \%$ o ) were mixed at room temperature and the polymerization reaction was conducted at $70{ }^{\circ} \mathrm{C}$ for $18 \mathrm{~h}$ under nitrogen atmosphere. The products were obtained by precipitating three times from $\mathrm{THF}$ in ethanol, followed by drying at $60{ }^{\circ} \mathrm{C}$ under vacuum for $12 \mathrm{~h}$.

\section{Preparation of Zn-coordinated PSVP (PSVP-Zn)}

In a typical experiment, $0.1 \mathrm{~g}$ PSVP was dissolved in $2 \mathrm{ml}$ toluene. Then, $0.032 \mathrm{ml} \mathrm{ZnCl}_{2} /$ ethanol $\left(0.1 \mathrm{~g} \mathrm{ml}^{-1}\right)$ was added to solution of PSVP and stirred for $2 \mathrm{~min}$. The solution was cast on copper sheet $(1 \times 1 \mathrm{~cm})$ to produce PSVP-Zn film with thickness of $0.24 \mathrm{~mm}$. Then, the PSVP-Zn film on copper sheet was hotpressed at $200{ }^{\circ} \mathrm{C}$ under $2 \mathrm{MPa}$. For mechanical and dielectric testing, $\mathrm{PSVP} / \mathrm{ZnCl}_{2}$ solution was charged in PTFE mold $(1 \times 5$ $\mathrm{cm})$ to allow the evaporation of solvents. The pre-formed strips were hot-pressed in molds at $200{ }^{\circ} \mathrm{C}$ under $2 \mathrm{MPa}$ to produce final strips for mechanical testing.

\section{Recycling of PSVP-Zn sample}

To investigate the removability of PSVP-Zn from copper substrates, the PSVP-Zn film on copper sheet were immersed in $5 \mathrm{ml}$ THF under ultrasonic at room temperature for $2 \mathrm{~h}$. The PSVP-Zn/THF solution was re-cased on copper sheets. Then, the PSVP-Zn film on copper sheet was hot-pressed at $200{ }^{\circ} \mathrm{C}$ under $2 \mathrm{MPa}$. To evaluate the mechanical, dielectric and thermal properties of recycled PSVP-Zn, as-prepared PSVP-Zn strips were dissolved in THF. The solution was re-charged in PTFE molds. After the evaporation of solvents, the pre-formed strips were hot-pressed in the molds at $200{ }^{\circ} \mathrm{C}$ under $2 \mathrm{MPa}$. Above procedures were recycled for three times to investigate the recyclability.

\section{Preparation of styrene-divinylbenzene copolymer (PSDVB)}

In this experiment, $1.0 \mathrm{~g}$ styrene, $0.14 \mathrm{~g}$ divinylbenzene and benzoylperoxide (BPO) $(5 \mathrm{wt} \%$ ) were mixed at room temperature and the solution is poured into the aluminum mold $(35 \times$ $10 \times 0.5 \mathrm{~mm})$. The polymerization was allowed to conduct at $70{ }^{\circ} \mathrm{C}$ for $8 \mathrm{~h}$ and at $100{ }^{\circ} \mathrm{C}$ for another $2 \mathrm{~h}$. Sample strips were got out from the molds and polished to the size of $30 \times 7 \times 0.3$ $\mathrm{mm}$.

\section{Characterization}

Fourier transform infrared spectroscopy (FTIR) was performed on the IS 5 (Thermo Fisher Scientific, USA) FTIR spectrometer. ${ }^{1} \mathrm{H}$ nuclear magnetic resonance (NMR) spectra were recorded on a FX201502 (600 MHz) using chloroform as solvent. Gel permeation chromatograph (GPC) was conducted on Waters
2695 (USA). Thermogravimetric analyses (TG) were performed on a simultaneous SDT Q600 thermal analyzer from TA Instruments (USA). The temperature range is room temperature to $800{ }^{\circ} \mathrm{C}$ with a heating rate of $10{ }^{\circ} \mathrm{C} \min ^{-1}$ under $\mathrm{N}_{2}$ atmosphere differential scanning calorimetric (DSC) measurements were made with an Instruments DSCQ2000 at room temperature to $200{ }^{\circ} \mathrm{C}$ and heating and cooling speed of $10{ }^{\circ} \mathrm{C} \mathrm{min}^{-1}$ under $\mathrm{N}_{2}$ atmosphere. Strain-stress curves were obtained on MTS C45.504E universal tensile testing machine with of 1 $\mathrm{mm} \min ^{-1}$. The strip dimensions were $40 \times 8 \times 0.1 \mathrm{~mm}^{3}$. Dielectric constant and dielectric loss of the resin were obtained on Agilent 4294A Impedance Analyzer varying frequencies at ambient temperatures.

\section{Results and discussion}

The chemical structure of as-prepared copolymers (PSVP) was characterized by ${ }^{1} \mathrm{H}$ NMR (Fig. 1a). The hydrogen signals of pyridine were found around $8.2 \mathrm{ppm}$. Peak integration indicates that the ratio of styrene/4-vinylpyridine units was around $92: 8$. GPC result indicates that the $M_{\mathrm{w}}$ of PSVP was $\sim 300,000 \mathrm{~g} \mathrm{~mol}^{-1}$ and polydispersity index was 2.39 (Fig. S1 $\dagger$ ). When directly incorporating $\mathrm{ZnCl}_{2}$ /ethanol solution into $\mathrm{PSVP} /$ toluene solution, gelation took place, indicating the cross-linking by coordination bonds. The resulted solution was precipitated in ethanol and the precipitates were dried in vacuum at $60{ }^{\circ} \mathrm{C}$. As produced polymer powders were dissolved in THF, cast in PTFE molds, and hot-pressed above $200{ }^{\circ} \mathrm{C}$ to give strips of styrene resins (PSVP-Zn). The strips were not dissolved in most of organic solvents, except tetrahydrofuran. It should be noted that linear PSVP was easily dissolved in good solvents, such as dioxane, chloroform, toluene. This suggested that cross-linking took place by incorporating $\mathrm{Zn}$ complexes in PSVP-Zn, as a result, endowing PSVP-Zn with stability in common solvents. The cross-linked structure of PSVP-Zn was characterized by FTIR (Fig. 1b). After introducing $\mathrm{Zn}^{2+}$ into PSVP, a newly emerging peak at $1614 \mathrm{~cm}^{-1}$ is observed, accompanied by the decrease of the absorption at $1600 \mathrm{~cm}^{-1}$, which indicates the formation of coordination bonds.

DSC curves showed that $T_{\mathrm{g}} \mathrm{S}$ of PSVP was increased from 108 to $117^{\circ} \mathrm{C}$ when incorporating $\mathrm{Zn}$ complexes (Fig. 2a). This result further verified the existence of cross-linking, which resulted in a reduction of chain mobility. TGA curves showed that $T_{\mathrm{d}}$ onset of PSVP-Zns was at $389{ }^{\circ} \mathrm{C}$ (Fig. 2b). The cross-linking by

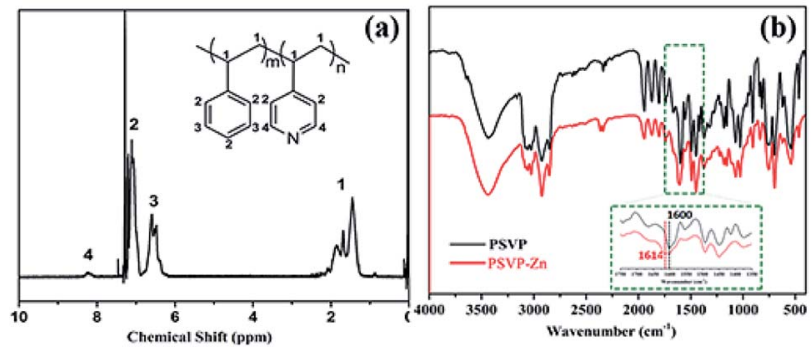

Fig. 1 (a) ${ }^{1} \mathrm{H}$ NMR spectrum of PSVP-Zn. (b) FTIR spectra of PSVP and PSVP-Zn. 

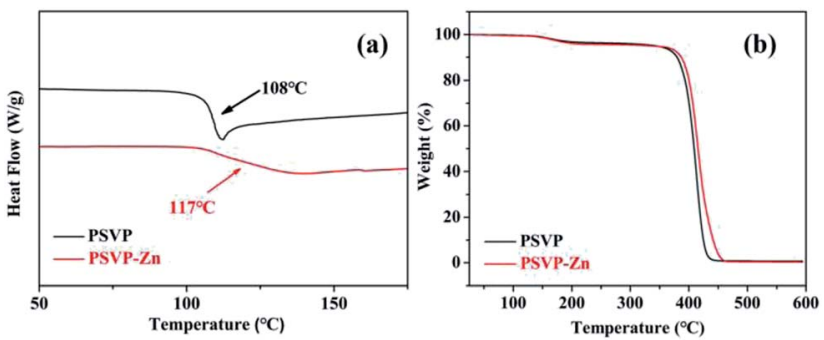

Fig. 2 (a) DSC curves of PSVP and PSVP-Zn; (b) TGA curves of PSVP and PSVP-Zn

coordination bonds seems not to improve thermal resistance of styrene resins. As shown in Fig. 3, tensile strength and Young's modulus of PSVP-Zns were higher than that of corresponding linear polymers (26.8 and $360 \mathrm{MPa}$ ). This result indicated that the cross-linking via coordination bonds enables great enhancement of mechanical strength. Besides, copolymer of styrene and divinylbenzene with feeding ratio of $95: 5$ (PSDVB) was prepared. From comparing the stress-strain curves of PSVP-Zn and PSDVB (Fig. 3), one can see that their tensile strength was almost identical ( $\sim 40 \mathrm{MPa})$.

It should be noted that the cross-linking by coordination bonds, as described above, is reversible rather than permanent. This feature may endow PSVP-Zn with recyclability. To show the removability of PSVP-Zn from integrated circuits, a simulation experiment was conducted. First, PSVP-Zn films were coated on copper substrate by solution casting and then the films on substrate were then immersed in THF to observe whether the PSVP-Zn films can be removed from the copper sheets (Fig. 4). From Fig. 4, after immersing the copper sheets in THF for 120 min followed by ultrasonic treatment, PSVP-Zn films were completely removed. However, when immersing the copper sheets in other solvents, such as DMF, ethanol, dioxane, DMSO, trichloromethane, ethylacetate, toluene, etc., the PSVP-Zn film can't be removed. Above results indicated that PSVP-Zn was removable by dissolving in specific solvents. This method is facile without destroying the substrates, thus providing a facile way to remove low dielectric media from integrated circuits.

The reprocessing of removed PSVP-Zn was also very convenient. To further evaluate the recyclability of PSVP-Zn, PSVP-Zn

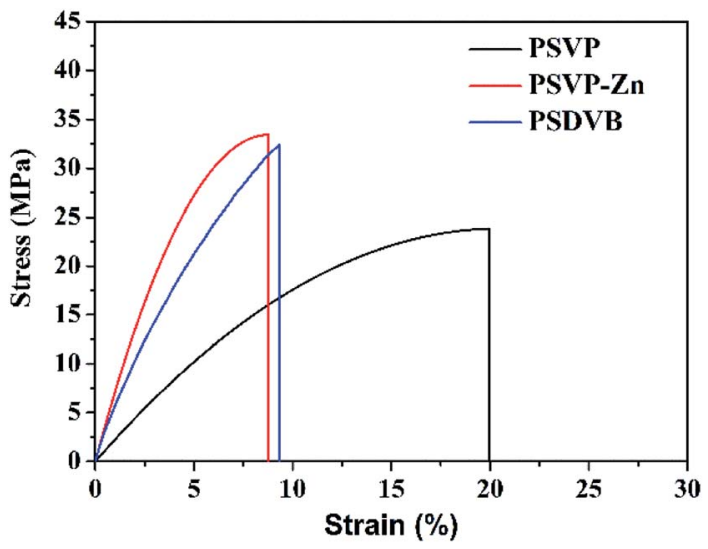

Fig. 3 Stress-strain curves of PSVP, PSVP-Zn and PSDVB.

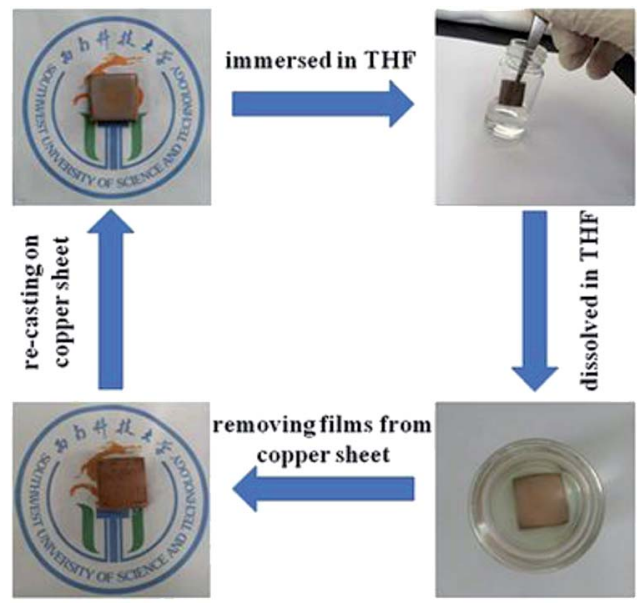

Fig. 4 Removing and recycling of PSVP-Zn on copper sheet.

strips were fabricated in PTFE molds. The strips were dissolved in THF. Then, the solution was cast in the molds followed by hot pressing at $200{ }^{\circ} \mathrm{C}$ under $2 \mathrm{MPa}$ to produce remolded strips. Above procedure was repeated for 3 times (Fig. 5a). The remolded strips were also found to undissolvable in organic solvents, indicating that the network structure was preserved. From the stress-strain curves, the tensile strengths and elongations at break of PSVP-Zn were decreased after recycling, while the modules were preserved (Fig. 5b). The extracted data was summarized in Table 1 . After third recycling, the tensile strength was $\sim 30.0 \mathrm{MPa}$, which was decreased by $11.7 \%$ as compared with that of original strips. However, the elongation at break was decreased to around $4.5 \%$, indicating that the polymer became fragile.

TGA curves indicate that the reprocessing of PSVP-Zn for 3 cycles just slightly affected the thermostability (Fig. 6a). From dielectric constant-lg(frequency) curves (Fig. 6b), the dielectric constants of recycled PSVP-Zn were slightly higher than that of original samples. It can be seen that after 3rd recycling, the dielectric constant of PSVP-Zn was 2.94, which was slightly increased by 0.24 as compared with that of original sample (Table 1). These results indicated that the reformed PSVP-Zn basically preserved the low dielectric property. Overall, no noticeable aging effect was found for PSVP-Zn after several cycles of reprocessing, thus indicating a good recyclability.

To further investigate the extreme number of cycling for PSVP-Zn, additional cycling was conducted. When the cycling number reached to 7 , the dielectric constant was only slightly
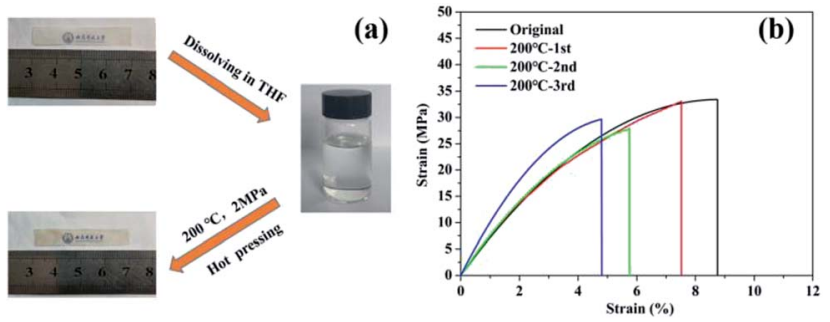

Fig. 5 (a) Reprocessing of PSVP-Zn strips; (b) stress-strain curves of original and regenerated PSVP-Zn films. 
Table 1 Dielectric properties, modulus, and strain of original and regenerated PSVP-Zn films

\begin{tabular}{llllll}
\hline Samples & Strain (MPa) & Modulus (MPa) & Elongation at break (\%) & Dielectric constant & Dielectric loss \\
\hline Original & $37.0 \pm 2.0$ & $790 \pm 80$ & $7.5 \pm 2$ & 2.70 & 0.01 \\
1st & $32.0 \pm 2.0$ & $690 \pm 70$ & $6.8 \pm 1$ & 2.71 & 0.01 \\
2nd & $31.0 \pm 3.0$ & $700 \pm 90$ & $5.8 \pm 2$ & 2.90 & 0.01 \\
3rd & $30.0 \pm 5.0$ & $730 \pm 100$ & $4.5 \pm 1$ & 2.94 & 0.01
\end{tabular}
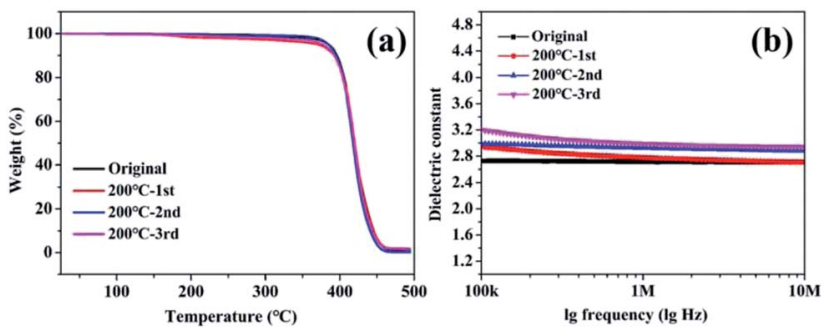

Fig. 6 (a) TGA curves of original and regenerated PSVP-Zn. (b) Dielectric constant changes as a function of $\lg$ frequency for original and regenerated PSVP-Zn films.

increased to $\sim 3.10$. However, the sample turned noticeable yellow (Fig. S2 $\dagger$ ) and became so fragile that the mechanical strength can't be measured. Thus, from the viewpoint of real application, it could be suggested that the extreme is not beyond 7 cycles. The high fragility could be attributed to the aging effect. Because the recycling use of PSVP-Zn requires the remolding at $200{ }^{\circ} \mathrm{C}$, the thermal degradation and ageing of PSVP-Zn appear to be inevitable. In particular, when the ageing results in secondary cross-linking via free radical reaction, the materials are susceptible to be more fragile although the modules could be increased.

\section{Conclusions}

4-Vinylpyridine was copolymerized with styrene to produce styrene polymers with ligands. Such polymers were crosslinkable when introducing $\mathrm{ZnCl}_{2}$. As-resulted styrene resins (PSVP-Zn) exhibited satisfactorily low dielectric constant and high thermal stability. More significantly, PSVP-Zn was removable from copper substrates via conveniently dissolving in THF. PSVP-Zn also exhibited good recyclability as it preserved the original mechanical strength and low dielectric constant after third cycling.

\section{Conflicts of interest}

There are no conflicts to declare.

\section{Acknowledgements}

The authors acknowledge the support and foundation from Innovation Team Project of Department of Science and Technology of Sichuan Province of China (16TD0014), Longshan academic talent research supporting program of Southwest University of Science and Technology (18LZXT02) and academic talent research supporting program of state Key Laboratory of Environmental-friendly Energy Materials (17fksy0102).

\section{Notes and references}

1 (a) K. Maex, M. R. Baklanov, D. Shamiryan, F. Iacopi, S. H. Brongersma and Z. S. Yanovitskaya, J. Appl. Phys., 2003, 93, 8793; (b) W. Volksen, R. D. Miller and G. Dubois, Chem. Rev., 2010, 110, 56-110; (c) T. L. Bucholz, S. P. Li and Y. L. Loo, J. Mater. Chem., 2008, 18, 530-536.

2 (a) Y. Liu, C. Qian, L. Qu, Y. Wu, Y. Zhang, X. Wu and S. Liu, Chem. Mater., 2015, 27, 6543-6549; (b) E. Y. Lee, I. S. Chae, J. Hong and S. W. Kang, Ind. Eng. Chem. Res., 2013, 52, 15713-15717; (c) W. H. Liao, S. Y. Yang, S. T. Hsiao, Y. S. Wang, S. M. Li, C. C. M. Ma and S. J. Zeng, ACS Appl. Mater. Interfaces, 2014, 6, 15802-15812.

3 (a) T. Maeda, H. Otsuka and A. Takahara, Prog. Polym. Sci., 2009, 34, 581-604; (b) C. J. Kloxin, T. F. Scott, B. J. Adzima and C. N. Bowman, Macromolecules, 2010, 43, 2643-2653; (c) W. Denissen, J. M. Winne and F. E. Du Prez, Chem. Sci., 2016, 7, 30-38.

4 (a) J. Kötteritzsch, S. Stumpf, S. Hoeppener, J. Vitz and M. D. Hager, Macromol. Chem. Phys., 2013, 214, 1636-1649; (b) X. Chen, M. A. Dam, K. Ono, A. Mal, H. Shen, S. R. Nutt, K. Sheran and F. A. Wudl, Science, 2002, 295, 1698-1702; (c) G. Zhang, Q. Zhao, L. Yang, W. Zou, X. Xi and T. Xie, ACS Macro Lett., 2016, 5, 805-808.

5 (a) D. Montarnal, M. Capelot, F. Tournilhac and L. Leibler, Science, 2011, 334, 965-968; (b) M. Capelot, M. M. Unterlass, F. Tournilhac and L. Leibler, ACS Macro Lett., 2012, 1, 789792.

6 (a) P. Cordier, F. Tournilhac, C. Soulié-Ziakovic and L. Leibler, Nature, 2008, 451, 977; (b) A. M. Kushner, J. D. Vossler, G. A. Williams and Z. Guan, J. Am. Chem. Soc., 2009, 131, 8766-8768; (c) J. Fox, J. J. Wie, B. W. Greenland, S. Burattini, W. Hayes, H. M. Colquhoun and S. J. Rowan, J. Am. Chem. Soc., 2012, 134, 5362-5368.

7 (a) D. Mozhdehi, S. Ayala, Q. R. Cromwell and Z. Guan, J. Am. Chem. Soc., 2014, 136, 16128-16131; (b) C. H. Li, C. Wang, C. Keplinger, J. L. Zuo, L. Jin, Y. Sun, P. Zheng, Y. Cao, F. Lissel, C. Linder, X. Z. You and Z. Bao, Nat. Chem., 2016, 8, 618-624; (c) L. L. Liu, S. Liang, Y. W. Huang, C. Y. Hu and J. X. Yang, Chem. Commun., 2017, 53, 12088-12091. 